\section{Skin conductance and reaction time with and without knowledge of results*}

\author{
M.P. COWLES \\ Atkinson College, York University, Toronto, Canada
}

Skin resistance was monitored during a simple reaction-time task carried out by two groups of Ss. Both groups were rewarded but only one group was given knowledge of results. Mean log basal conductance level was negatively and significantly related to reaction time in the no-knowledge-of-results group. No such relationship was found for the knowledge-of-results group, which had significantly faster reaction times. There was no significant difference between mean $\log$ basal conductance level in the two groups. The results suggest that basal skin conductance level does not reflect activity in a postulated reinforcement system.

McCormack (1962, 1967a) has postulated an inhibition-motivation theory that accounts for the findings of reaction-time and signal-detection experiments in which performance remains stable over time under conditions where reinforcement is provided by giving knowledge of results (KR). He suggests (1967a) that an investigation in which skin conductance is monitored during tasks involving KR "might well reveal important information concerning the nature of the postulated reinforcement mechanism." Skin conductance levels seem to be a popular way of defining level of arousal or activation. Behavioral definitions are much less clear. Duffy (1962) and Malmo (1958) tend to equate the concept of activation with intensity of motivation or drive level. This has led some researchers to attempt to measure motivation or drive level by recording skin conductance levels. Although the concepts of activation and drive would seem to be related at almost any behavioral definition level, to equate both these concepts with a single physiological index appears to be a gross oversimplification. Coules \& Avery (1966) report results which they say are contrary to McCormack's theory. They found that in a no-knowledge-of-results (NKR) situation, males showed high mean levels of skin conductance and that this shows "that this situation is not one of low motivation or an inhibition state." However, McCormack (1967b), after examining these findings, points out that they are not in fact at variance with his proposals. All Ss showed a performance decrement in the NKR situation; males showed an improvement and females a smaller decrement in the KR condition, though these differences with a small sample size were not statistically significant. McCormack clarified the confusion by

*This research was carried out at the University of Edinburgh, Scotland. stating that his construct was not physiologically based but was "purely a quantitative one expressed as a mathematical function of certain experimental variables." Briefly, McCormack sees an inhibitory state as developing over time in the absence of KR reinforcement and overall drive level as being "inversely related to the degree of variability of stimulus presentation." Giving monetary rewards will affect drive level; drug states and the "intensity and frequency of the signal" are also possible factors.

Does manipulation of motivational and reinforcement variables (for example, giving KR) in fact affect not only performance but also "activation" as defined by skin conductance level? Is it really possible to relate a NKR situation necessarily with a low-motivation or inhibition state, and to relate this state in a simple fashion with low levels of skin conductance? A number of NKR vigilance-type tasks, e.g., Eason et al (1965), have involved Ss who have registered high skin conductance levels. Corteen (1967) measured skin conductance and reaction time concurrently in a NKR situation. Results showed that conductance level was related to mean optimum response time (the mean of the five fastest RTs in a set of 10 trials). Corteen reemphasises the suggestion put forward by Corteen \& Blackman (1965) that "tonic" or long-term activation needs to be distinguished from "phasic" short-term activation and that basal level of skin conductance is related to tonic activation. Further, Corteen suggests that tonic activation level cannot be altered by changes in the environment, that manipulation of the level of stimulation affects not tonic activation but "drive," which he expresses as "the discrepancy between the optimum stimulation level for a given level of tonic activation and the actual level presented by the situation."
Mere manipulation of KR does not, of course, exhaust the possible motivational variables in this type of research. Coules and Avery's Ss were rewarded, for they were paid research assistants. Corteen's Ss were students in his lecture and practical programs. Experience in the writer's department has shown that faster RTs are often obtained in experiments conducted by a faculty member than in those conducted by a senior student, even though both used $\mathrm{S}$ samples drawn from the same student population. No student wishes to appear "slow" to his tutors and examiners. He tries harder. In the present study, an attempt was made to ensure that the Ss tried to do well in what after all might otherwise have been a boring situation by a system of differential rewards. Its main purpose was to determine differences, if any, in skin conductance levels and performance levels in a KR and a NKR RT task and to try to verify reported relationships between skin conductance level and performance.

\section{METHOD}

Ss were 37 male volunteers. They were university students and senior schoolboys with ages ranging from 17 to 32 years (mean 20.3 years). They were assigned randomly to the KR or NKR groups. The KR group then had an N of 16 and the NKR group an $N$ of 21. All Ss were familiar with the laboratory surroundings and general procedure, since they had previously taken part in work involving the recording of physiological indices, though this particular experiment was, of course, new to them. Ss sat in an $8 \times 8 \times 6 \mathrm{ft}$ sound-attenuated cubicle, on a comfortable padded chair, before a small table on which was mounted a black perspex panel (11 $x 5$ in.) set at an angle of $20 \mathrm{deg}$ to the horizontal and raised $2 \frac{1}{2}$ in. from the table surface at its lowest point. Set in the center of the panel was a black "reaction" button, $5 / 16$ in. in diam. Two inches above this was a yellow lamp, and above the yellow lamp, a red neon lamp, both lamps being $1 / 2$ in. in diam. The yellow lamp served as a "ready" signal and the red lamp as the reaction stimulus. Outside the cubicle the E's control panel enabled a foreperiod of 1 , $2,3,4$, or $5 \mathrm{sec}$ to be selected. After selecting a foreperiod, the $E$ pressed an activating switch that illuminated the yellow lamp and simultaneously started the foreperiod timing operation (controlled by a C-R time-constant circuit of the appropriate value for the desired foreperiod). At the end of the foreperiod, the red light was automatically illuminated and simultaneously an electronic timer capable of reading from 0 to $.999 \mathrm{sec}$ started. Pressing the reaction button 
stopped the timer and extinguished the reaction lamp.

Skin resistance was recorded via two Beckman Biopotential skin electrodes, one placed in the center of the palm, the other towards the thenar eminence, the centers of the electrodes being $13 / 16$ in. apart. A third ground electrode was placed on the forearm. The electrode sites were cleaned with "Phisohex" (Bayer Products Co.). Electrode cups were filled with Offner paste and the electrodes attached by means of double adhesive collars. A Beckman Type $\mathrm{R}$ Dynograph recorder and skin resistance preamplifier coupler, Type $9892 \mathrm{~A}$, in the E's room were used to record continuously the Ss' skin resistance level. Current across the electrodes was provided from a 4.05.V Mallory mercury cell. All Ss used the forefinger of the preferred hand for pressing the reaction button and the electrodes were attached to the nonpreferred hand. For Ss in the KR group, a second electronic timer paralleled with the E's timer was placed on the cubicle table, giving these Ss immediate KR after each trial. The $E$ recorded reaction times on a printed form on which the five foreperiods had been randomly entered 10 times, thus giving a sequence of 50 trials.

After entering the cubicle, each $S$ was asked to relax for $5 \mathrm{~min}$ before the experiment began. After $5 \mathrm{~min}$, the $\mathrm{E}$ entered the cubicle and gave the following instructions: "This is a reaction-time experiment. Sit with your forefinger on the button and watch for the yellow light. This is your "get ready" light. A short time after the yellow light comes on, the red light will come on. This time is variable, but as soon as the red light comes on, press the button. Release it after a moment or two and wait for the next trial. O.K.?

"In order to give you some incentive, you'll be paid on a sliding scale according to your speed. For every reaction time of less than $0.2 \mathrm{sec}$ you'll be paid $3 \mathrm{~d}$, between 0.2 and $0.225,2 \mathrm{~d}, 0.225$ to $0.25,1 \mathrm{~d}$, and slower than $0.25 \mathrm{sec}$, nothing. It is possible to earn over 12 shillings but most people get something between 6 and 10 shillings. The faster you are the more you'll be paid."

The operation of the timer was explained to Ss in the KR group "so that you can see how you are getting along."

Presentation of the stimulus was determined by the pen recording skin resistance having reached a steady base line, the coupler bridge being rebalanced where necessary as the experiment continued. The length of the series of trials varied from 10 to $21 \mathrm{~min}$ (mean 15.5, SD 2.7).

\section{RESULTS}

For each $S$ the best reaction time and

\begin{tabular}{lcc}
\hline Pearson "r" between: & Table 1 & $\mathrm{KR}$ \\
\hline $\begin{array}{l}\text { Mean RT and mean } \\
\text { log conductance }\end{array}$ & $-.30 \mathrm{NRR}<.1$ & $.04 \mathrm{n} . \mathrm{s}$. \\
$\begin{array}{l}\text { Mean best } 10 \mathrm{RT} \text { and } \\
\text { mean log conductance }\end{array}$ & $-.56 \mathrm{p}<.01$ & $-.08 \mathrm{n}$.s. \\
$\begin{array}{l}\text { Best RT and mean } \\
\text { log conductance }\end{array}$ & $-.52 .01<\mathrm{p}<.02$ & $-.13 \mathrm{n} . \mathrm{s}$. \\
\hline
\end{tabular}

the best 10 reaction times were extracted from the record and mean $\mathrm{RT}$ and mean of the best 10 RTs calculated. This follows Corteen's (1967) procedure of selecting the fastest times and again looks at Taylor's (1965) suggestion that the fastest reaction time in a series might not be related to activation level. From the Dynograph record, basal resistance at the start of each RT series and at 1-min intervals throughout the series was extracted for each $\mathrm{S}$. These readings were converted into conductance (millimicromhos) and mean $\log$ conductance levels were calculated. Plots of the variables show no evidence of curvilinearity. For the NKR group, mean of the mean RTs was $253.8 \mathrm{msec}$, SD 27.3; mean of the mean of the best 10 RTs was $213.3 \mathrm{msec}, \mathrm{SD} 19.9$; mean of best RTs was $194.3 \mathrm{msec}, \mathrm{SD} \mathrm{22.6}$; mean of the mean $\log$ conductances was 3.912 , $\mathrm{SD} 0.18$. For the KR group, these values were: $225.6 \mathrm{msec}$, SD 20.7; $189.6 \mathrm{msec}$, SD 15.2; $175.6 \mathrm{msec}$, SD 16.8; $3.855 \mathrm{msec}$, SD 0.15 .

The results summarized in Table 1 show that when $\log$ conductance is used as a measure of tonic activation level the relationship between activation level and reaction time holds only in the NKR situation.

Table 2 indicates that $\mathrm{KR}$ does provide additional reinforcement but does not seem to affect tonic activation level.

$$
\text { DISCUSSION }
$$

Whatever the nature of the reinforcing mechanism connected with KR, it does not seem to be directly linked with the mechanism responsible for maintaining tonic activation level. The results provide support for Corteen's finding of a relationship between reaction time and basal skin conductance and his suggestion that manipulation of the level of stimulation (in this case by providing $K R$ ) does not affect tonic activation. We might regard tonic activation level as an index of

Table 2

\begin{tabular}{ll}
$\begin{array}{c}\text { Student's } t \\
\text { for differences } \\
\text { between means: }\end{array}$ \\
\hline Mean RTs & $3.35 \quad \mathrm{p}<.01$ \\
Mean best 10 RTs & $3.85 \quad \mathrm{p}<.01$ \\
Best RTs & $2.70 .01<\mathrm{p}<.02$ \\
Mean log conductances & 1.01 n.s. \\
\hline
\end{tabular}

general efficiency, this efficiency being perhaps best measured by the individual's better performances rather than his mean level. Short-term improvement in performance brought about by additional reinforcement does not affect this level of general efficiency or the level of tonic activation that it reflects. Tonic activation level is not the same thing as level of motivation, and an important conclusion must be that loose definitions of drive and motivation vaguely associated with activation can only lead to confusion.

Routtenberg $(1966,1968)$ has postulated two anatomically distinct arousal systems. Arousal System I is closely related to the ascending reticular arousal system described by Moruzzi \& Magoun (1949). Arousal System II is part of the limbic midbrain system and its role in behavior is based on the work of Olds \& Milner (1954) on the phenomenon of self-stimulation. The concept of two systems, one concerned with the organization for a response and the other a reward system, though not fully understood, is not at variance with the notion of a long-term activation system that reflects the overall efficiency of the individual and a short-term system, the action of which is much more dependent $\mathrm{u}$ p o $\mathrm{m}$ ore im mediate circumstances $\rightarrow$ stimulus input, reinforcement, and the like. It seems highly likely that activity in two such hypothesized systems will have different effects upon "peripheral" physiological activity, depending upon which system is most active and which physiological index is being studied at any one time. Indeed, it is known that stimulation of different areas of the limbic system can produce opposite effects at the periphery. The results reported here might be explained in terms of the increased reward that $\mathrm{KR}$ brings activating the hvpothesized reward system, thus producing behavior that is superior to the usual level of efficiency but not affecting basal level of skin conductance that reflects that level.

\section{REFERENCES}

CORTEEN, R. S. Basal conductance level and motor performance. British Journal of Psychology. 1967, 58, 111-112.

CORTEEN, R. S., \& BLACKMAN, R. Skin conductance change and sensory 
discrimination. British Journal of Psychology, $1965,56,431-437$.

COULES, J., \& AVERY, D. L. Human performance and basal skin conductance in a vigilance-type task with and without knowledge of results. Perceptual \& Motor Skills, 1966, 23, 1295-1302.

DUFFY, E. Activation and behavior. New York: Wiley, 1962.

EASON, R. G., BEARDSHALL, A., \& JAFFEE $S$. Performance and physiological indicants of activation in a vigilance situation. Perceptual \& Motor Skills, 1965, 23, 3-13.

MCCORMACK, P. D. A two-factor theory of vigilance. British Journal of Psychology, 1962, 53, 357-363.

MCCORMACK, P. D. A two-factor theory of vigilance in the light of recent studies. In A. F. Sanders (Ed.), Attention and performance. Amsterdam: North-Holland, 1967a. Pp. 400-409.

McCORMACK, P. D. Reply to Coules and Avery. Perceptual \& Motor Skills, 1967b, 25, 256.

MALMO, R. B. Measurement of drive: An unsolved problem in psychology. In M. R. Jones (Ed.), Nebraska symposium on motivation. Lincoln: University of Nebraska Press, 1958. Pp. 229-265.

MORUZZI, G., \& MAGOUN, H. W. Brain stem reticular formation and activation of the EEG. Electroencephalography \& Clinical Neurophysiology, 1949, 1, 455-473.

OLDS, J., \& MILNER, P. Positive reinforcement produced by electrical stimulation of septal area and other regions of rat brain. Journal of Comparative \& Physiological Psychology, 1954, 47, $419-427$.

ROUTTENBERG, A. Neural mechanisms of sleep: Changing view of reticular formation function. Psychological Review, 1966, 73, 481-499.

ROUTTENBERG, A. The two-arousal hypothesis: Reticular formation and limbic system. Psychological Review, 1968, 75, 51-80.

TAYLOR, D. H. Two dimensions for reaction time distributions. Nature (London), 1965, 206, 219-220.

\title{
Comparison of associative learning strategies
}

\author{
GORDON H. BOWER* and DAVID WINZENZ \\ Stanford University, Stanford, Calif. 94305
}

Ss learned paired-associate lists of nouns using one of four learning strategies: repetition of the pair, reading the pair as subject and object nouns in a meaningful sentence, generation of a meaningful sentence linking the two nouns, or visualization of a mental image in which the word referents were in vivid interaction. Half of the pairs were tested for recall of the response member given the stimulus and half were tested for multiple-choice recognition of the response. Significant differences in recall and recognition occurred with conditions ranking in the order: imagery (best), sentence generation, sentence reading, and rote repetition (worst). The results are interpreted in terms of associative consequences of relational organization: S's memory benefits from his actively searching out, discovering, and generating (or depicting) predicative or "actor-action-object" relations between the words or referents of a pair.

This experiment is concerned with the effect of various learning strategies upon paired-associate learning by college Ss. Ss spontaneously use many different techniques to learn paired associates; with noun pairs, the techniques may range from simple repetition to the construction of catchy phrases or elaborate narratives woven around the word pair. Rohwer (1966) reported that reading young children a declarative sentence linking the S-R pair as subject and object nouns produced better recall than having the children simply study the pair without a sentence context. Further, Bobrow \& Bower (1969) found that college students

*This research was supported by Grant MH-13950 to the first author from the National Institute of Mental Health. remembered a noun pair much better if they generated their own sentence linking the word pair rather than just studying the pair embedded in a sentence constructed by E. Finally, Bower (in press) cites evidence that having $S$ form a mental picture of the words' referents in vivid interaction produces somewhat better learning than does having $S$ generate a sentence linking the word pair. Comparing across these several studies, there seems to be a progressive improvement in recall going from rote repetition to studying the word pair in a sentence, to generating a sentence linking the pair, to forming an interactive mental image. The following experiment compares these several learning strategies within one experiment and one $S$ population, using both recall and recognition tests of associative learning.
Conceivably, the differences among conditions are attributable solely to differences in response availability. If so, then differences among the conditions in recall performance would disappear in tests of recognition memory.

\section{METHOD}

Three paired-associate lists of 30 items each were constructed using unrelated concrete nouns. Each $S$ learned and recalled all lists. Study times and test times were $5 \mathrm{sec}$ per item. After one study trial on each list, an "immediate" test followed for the items of that list. The test stimuli were presented in the same order as that in which the pairs had been studied, thus assuring a constant lag of 30 items between studying and testing each pair. After the three lists had been studied and tested once each, a final test was given to all 90 pairs. On both immediate and final tests, half the items were tested for cued recall and half by multiple-choice recognition. The recognition test presented the cue word followed by five response words from the appropriate list; $S$ was to select and say aloud the correct response that had been paired with the cue word. No feedback was given on test trials.

Each $\mathrm{S}$ was assigned randomly to one of four groups, received general paired-association instructions, and then was instructed specifically on how to memorize the S-R pairs. In the repetition condition, $S$ was asked to repeat or rehearse each pair silently to himself during the study time. In the sentence-reading condition, $\mathrm{S}$ saw each pair as capitalized subject and object nouns in a simple declarative sentence, was told to read the sentence aloud and use it to associate the two critical nouns. In the sentence-generation condition, $S$ was shown each pair and asked to make up and say aloud a meaningful sentence or phrase using and relating the two words in a sensible way. In the imagery condition, $S$ was asked to visualize a mental picture or image in which the two referents (denoted by the words) were in some kind of vivid interaction. He was encouraged to make his image as elaborate, vivid, or bizarre as he wished. The Ss were 40 undergraduates fulfilling a service requirement for their introductory psychology course, with 10 Ss assigned to each of the four learning conditions.

\section{RESULTS}

The average number of correct responses per list (15 recall and 15 recognition items) is given in Table 1 for the four types of learning conditions. "Immediate" in Table 1 denotes tests given just after each set of 30 items had been studied. "Final" denotes the test of all items at the end of the session after the three lists had been 